\title{
Genetic diversity analysis of oriental river prawn, Macrobrachium nipponense, in Yellow River using microsatellite marker
}

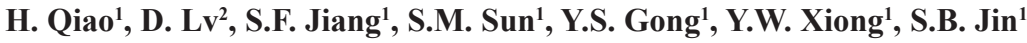
and H.T. $\mathrm{Fu}^{1}$

${ }^{1}$ Key Laboratory of Freshwater Fisheries and Germplasm Resources Utilization, Ministry of Agriculture, Freshwater Fisheries Research Center, Chinese Academy of Fishery Sciences, Wuxi, China

${ }^{2}$ Wuxi Fishery College, Nanjing Agricultural University, Wuxi, China

Corresponding author: H.T. Fu

E-mail: fuht@ffrc.cn

Genet. Mol. Res. 12 (4): 5694-5703 (2013)

Received November 30, 2012

Accepted February 4, 2013

Published November 18, 2013

DOI http://dx.doi.org/10.4238/2013.November.18.18

\begin{abstract}
To assess the genetic status of this species, the genetic diversity of wild Macrobrachium nipponense from seven geographic locations in the Yellow River basin were investigated using 20 polymorphic microsatellite DNA loci. The genetic diversity between populations was indicated by the mean number of alleles per locus and mean observed heterozygosity $(\mathrm{H})$ and the expected $\mathrm{H}$, which was arranged from 2 to 10 , from 0.4705 to 0.5731 , and from 0.5174 to 0.6146 , respectively. Hardy-Weinberg equilibrium analysis indicated that a deficiency of heterozygotes existed in all seven populations. Both the $F_{\mathrm{ST}}$ and AMOVA analyses showed that there is significant difference on population differentiation among populations. The UPGMA clustering tree demonstrated that their close relationship is consistent with their geographic proximity. The
\end{abstract}


data suggest that this Yellow River population has a wide genetic base that is suitable for breeding.

Key words: Macrobrachium nipponense; Genetic diversity; Yellow river; Microsatellite marker

\section{INTRODUCTION}

Oriental river prawn (Macrobrachium nipponense) is widely distributed in Southeast Asian countries (Yu and Miyake, 1972; Cai and Ng, 2002). As an indigenous species, it has a wide range of distribution from the southern to the northern parts of China, including rivers, lakes, reservoirs, and ditches. In recent years, the farming production of $M$. nipponense has increased quickly and reached $20.5 \times 10^{5}$ metric tons in 2008 (Bureau of Fishery et al., 2009). The increasingly economic importance of oriental river prawn culture in China prompted the current study to assess the relative levels of its genetic diversity.

The genetic definition of stocks has been a major concern in understanding natural resources to ensure the sustainability of shrimp resources. Because different broodstocks or seedstocks might differ in growth rate, or disease resistance, among other characteristics (Klinbunga et al., 2001), the identification of wild shrimp stocks is also important to provide an available source of wild genetic diversity in domestication and selective breeding programs (Brooker et al., 2000; Klinbunga et al., 2001). Currently, relative studies on $M$. nipponense have mainly focused on the development of molecular markers (Feng and Li, 2008; Zhao et al., 2010; Qiao et al., 2011; Song and Kim, 2011) and genetic diversity of the wild populations from the south rivers, mainly in the Yangtze River Basin and Qiantang River (Fu et al., 2010; Feng et al., 2011; Ge et al., 2011; Ma et al., 2011; Su et al., 2011). Previous studies on the genetic diversity of wild $M$. nipponense were mainly focused on the geographic populations of Yangtze River, Qiantang River, Taihu Lake, Poyang Lake, and Hongze Lake. Considering the fact that the Yellow River is second to the combined Ganges/ Brahmaputra river system in suspended sediment load, with an estimated 1.6 billion tons of sediment annually (Milliman and Meade, 1983), research knowledge of the genetic structure and diversity of the natural crustacean populations in the Yellow River is limited. Among the molecular markers available in population genetics, microsatellite DNA markers are a useful tool for evaluating the genetic diversity and structure of various species, owing to their high variability, abundance, neutrality, co-dominance, and unambiguous scoring of alleles (Brooker et al., 2000). Previous studies have revealed the presence of subtle genetic structures at small and large geographic scales in the crustacean, such as Penaeus monodon (Brooker et al., 2000; Supungul et al., 2000).

Our hypothesis is that M. nipponense could be genetically structured along its latitudinal range of distribution owing to geographic heterogeneity. In this study, seven wild populations of $M$. nipponense were collected in or nearby the main stream of Yellow River from upstream to downstream. Twenty microsatellite markers previously developed by our laboratory were used to reveal the genetic structure and variability of wild $M$. nipponense in the Yellow River, to supply necessary information about genetic variations in different populations for setting up breeding and resource conservation programs of $M$. nipponense. 


\section{MATERIAL AND METHODS}

\section{Sample collection}

Seven wild populations of oriental river prawn were collected from four provinces through which the Yellow River flows, to represent the wild genetic resources in the Yellow River, with 39 individuals from each area. Three sampling sites from downstream (Table 1) were Dongying (DY), Jinan (JN), and Dongming (DM) in Shandong Province. Three sampling sites from midstream were Jiyuan (JY) and Sanmenxia (SM) in Henan Province, and Pianguan (PG) in Shanxi Province. The only sampling site from upstream was Yinchuan (YC) in Ningxia Province, because the sediment concentration and turbulent waters of most upstream sites were not suited for survival.

\begin{tabular}{|c|c|c|c|}
\hline Location & Sampling date & No. specimens & Sites \\
\hline Dongying (DY) & October 2010 & 39 & $37^{\circ} 36^{\prime} \mathrm{N}, 118^{\circ} 45^{\prime} \mathrm{E}$ \\
\hline Jinan $(\mathrm{JN})$ & November 2010 & 39 & $36^{\circ} 39^{\prime} \mathrm{N}, 116^{\circ} 48^{\prime} \mathrm{E}$ \\
\hline Dongming (DM) & November 2010 & 39 & $35^{\circ} 23^{\prime} \mathrm{N}, 115^{\circ} 06^{\prime} \mathrm{E}$ \\
\hline Jiyuan (JY) & December 2010 & 39 & $34^{\circ} 55^{\prime} \mathrm{N}, 112^{\circ} 26^{\prime} \mathrm{E}$ \\
\hline Sanmenxia (SM) & December 2010 & 39 & $34^{\circ} 36^{\prime} \mathrm{N}, 111^{\circ} 10^{\prime} \mathrm{E}$ \\
\hline Pianguan (PG) & July 2011 & 39 & $39^{\circ} 19^{\prime} \mathrm{N}, 111^{\circ} 24^{\prime} \mathrm{E}$ \\
\hline Yinchuan (YC) & July 2011 & 39 & $38^{\circ} 22^{\prime} \mathrm{N}, 106^{\circ} 25^{\prime} \mathrm{E}$ \\
\hline
\end{tabular}

\section{DNA extraction and PCR}

Samples from each site were stored separately in $95 \%$ ethanol in a $-20^{\circ} \mathrm{C}$ until DNA extraction. Genomic DNA was extracted from muscle using the traditional proteinase-K digestion and phenol-chloroform extraction protocol (Sambrook and Russell, 2001).

Twenty polymorphic microsatellite loci (Qiao et al., 2011) with high expected heterozygosity values were used to investigate the genetic relationships among the seven wild oriental river prawn populations, distributed in Yellow River. The primer sequences and characteristics are listed in Table 2. PCR amplification was carried out in a $25 \mu \mathrm{L}$ reaction volume, containing $1 \mathrm{X}$ PCR buffer (Tiangen, Beijing, China), 30 to $50 \mathrm{ng}$ genomic DNA, 0.25 $\mu \mathrm{M}$ each primer, $150 \mu \mathrm{M}$ dNTPs, $1.5 \mathrm{mM} \mathrm{MgCl}_{2}$, and $0.5 \mathrm{U}$ Taq DNA polymerase (Tiangen). The PCR conditions were as follows: the DNA was first denatured at $94^{\circ} \mathrm{C}$ for $3 \mathrm{~min}$, followed by 30 cycles including denaturation at $94^{\circ} \mathrm{C}$ for $30 \mathrm{~s}$, annealing at $50-64^{\circ} \mathrm{C}$ (Table 2) for $30 \mathrm{~s}$, and elongation at $72^{\circ} \mathrm{C}$ for $40 \mathrm{~s}$, and a final elongation at $72^{\circ} \mathrm{C}$ for $10 \mathrm{~min}$. The PCR products were size-fractionated on $6 \%$ polyacrylamide gels with silver staining. The pBR322 DNA/ BsuRI (HaeIII) marker (Fermentas, Shenzhen, China) was used to determine the allele sizes.

\section{Statistical analysis}

The probability of the occurrence of null alleles and scoring error were tested using Micro-Checker (Van Oosterhout et al., 2004). The PopGen32 software (version 1.31; available at http://www.ualberta.ca/ fyeh/) was used to analyze allele frequencies, observed $\left(H_{\mathrm{O}}\right)$ and expected heterozygosities $\left(H_{\mathrm{E}}\right)$ for each locus, genetic distance $(D)$, genetic identity $(I)(\mathrm{Nei}, 1978)$, statistical significance of Hardy-Weinberg equilibrium (HWE), and cluster analysis. Population 
pairwise $F_{\mathrm{ST}}$ values based on the number of different alleles and allele frequencies were calculated using analysis of molecular variance (AMOVA) with GenAlEx6 (Peakall and Smouse, 2006; available at http://www.anu.edu.au/BoZo/GenAlEx/). The polymorphism information content (PIC), a measure of locus polymorphism, was estimated using the formula of Botstein et al., (1980). F-Statistics were calculated and their significance was tested using FSTAT version 2.9.3 (Goudet, 1995). Significance values for pairwise comparisons of population differentiation were Bonferroni corrected to account for multiple comparisons. Clustering analyses were performed using the MEGA software (version 4.1; available at http://www.megasoftware.net/ mega4/mega41.html) to calculate the genetic similarity matrices, and the dendrograms were constructed by the unweighted pair-group method of arithmetic averages (UPGMA).

\section{RESULTS}

\section{Genetic diversity across 20 loci and 7 populations}

All of the microsatellite loci showed sufficient polymorphism for evaluating the genetic diversity of $M$. nipponense. Null alleles were not detected from each locus through the analysis by Micro-Checker. A total of 103 alleles were detected at the 20 microsatellite loci assayed in 7 wild M. nipponense populations, and the average number of alleles per locus was 5.15, with the range of 2 to 10 . The values of $H_{\mathrm{O}}$ ranged from 0.2644 to 0.7949 , with a mean of 0.5081 . The values of $H_{\mathrm{E}}$ ranged from 0.2783 to 0.7885 , with a mean of 0.6003 . The average observed heterozygosity was less than the expected $(0.5081 \pm 0.1619$ and $0.6003 \pm 0.1773$, respectively). The mean PIC was 0.5575 , ranging from 0.2811 to 0.7885 (Table 2). Apparently, the above-mentioned data showed a relatively higher genetic diversity of wild oriental river prawn in the Yellow River.

The mean number of alleles (MNE) was different among populations. The MNE in the seven populations varied from 3.5500 to 4.7000 . The SM and DM populations were the most diverse populations, with the highest allelic richness at 4.7 and 4.65 respectively. $H_{\mathrm{O}}$ and $H_{\mathrm{E}}$ were slightly different amongst the populations from different sites. SM had the highest $H_{\mathrm{O}}(0.5731)$ and $H_{\mathrm{E}}(0.6146)$. YC and PG had relatively lower $H_{\mathrm{O}}$ values $(0.4718$ and 0.4705 , respectively). YC had the lowest $H_{\mathrm{E}}(0.5174)$ amongst the populations (Table 3$)$.

Of 140 population-locus cases (7 populations $\mathrm{x} 20$ loci) examined by Hardy-Weinberg tests, $91(65.0 \%)$ were in HWE $(\mathrm{P}>0.05)$, whereas the other $48(34.3 \%)$ showed significant deviation $(\mathrm{P}<0.05)$. An exact $\mathrm{P}$-value test indicated that most loci significantly deviated from HWE in the DY and JN populations with the number of 10 loci, respectively $(\mathrm{P}<0.05)$. The deviations of HWE were also detected in the other 5 populations with the number of 7 in DM, 6 in JY, 7 in SM, 7 in PG, and 8 in YC. The $F_{\text {IS }}$ value verified that most loci presented heterozygote deficiencies $\left(F_{\text {IS }}>0\right.$, Table 4$)$.

\section{Population genetic differentiation}

The population differentiation was revealed by a pairwise $F_{\mathrm{ST}}$ coefficients matrix. According to the values of the matrix, the $F_{\mathrm{ST}}$ coefficients ranged from 0.0172 (between DY and $\mathrm{DM})$ to 0.0791 (between PG and JY). The P-values for any other two geographic populations $(\mathrm{P}<0.05)$ indicated a genetic differentiation between any of these two populations (Table 5). AMOVA for the seven populations based on 20 microsatellite loci showed $83.61 \%$ of the total 
genetic variation within the individuals. The genetic variation among populations and between individuals among populations was 6.04 and $9.42 \%$, respectively. Statistical analysis showed a significant difference for the three variations $(\mathrm{a}=0.01$, Table 6$)$.

\begin{tabular}{|c|c|c|c|c|c|c|c|}
\hline Locus (accession No.) & Sequence (5' to $3^{\prime}$ ) & $\mathrm{Ta}\left({ }^{\circ} \mathrm{C}\right)$ & $\begin{array}{l}\text { Product } \\
\text { size (bp) }\end{array}$ & $\begin{array}{l}\text { No. of } \\
\text { alleles }\end{array}$ & $H_{\mathrm{O}}$ & $H_{\mathrm{E}}$ & PIC \\
\hline WXM01 & F: TTCCCCACGCACCTCAAT & 54 & $96-100$ & 3 & 0.2967 & 0.4241 & 0.3826 \\
\hline (GU189600) & R: GACATCCATGCAAAGCAACAG & & & & & & \\
\hline WXM02 & F: GCCATTTTCTCATAAGGGT & 52 & $172-220$ & 10 & 0.7546 & 0.7892 & 0.7634 \\
\hline (GU189601) & R: ACGGTGGTATTCAGGGAT & & & & & & \\
\hline WXM03 & F: AGAGGCAATTGTAGCCGAGA & 54 & $192-245$ & 4 & 0.5897 & 0.6601 & 0.5993 \\
\hline (GU189602) & R: TGGCACGATAGGAAGGAGTT & & & & & & \\
\hline WXM05 & F: ATCCTGCGAAGATCATACGG & 50 & $158-185$ & 8 & 0.6703 & 0.8156 & 0.7885 \\
\hline (GU189604) & R: TGCATTTGCAATCCACTCAT & & & & & & \\
\hline WXM06 & F: TTGGCAAGTCTCGTCTGATG & 54 & $132-172$ & 6 & 0.7216 & 0.8127 & 0.7833 \\
\hline (GU189605) & R: CGAGGA AACGCCTGCTAC & & & & & & \\
\hline WXM07 & F: CGACGAGGCAACAGAATA & 50 & $234-267$ & 5 & 0.5604 & 0.6370 & 0.5631 \\
\hline (GU189606) & R: TGATAATGCGAGGGAGTAA & & & & & & \\
\hline WXM09 & F: GTCACTGACTATGAACAATAACA & 46 & $116-145$ & 4 & 0.4066 & 0.5184 & 0.4503 \\
\hline (GU189608) & R: GGTTTGATCTGGAAGTTTAG & & & & & & \\
\hline WXM13 & F: ATGAAGGTAAGTGGCTGAGA & 54 & $165-206$ & 7 & 0.6923 & 0.7860 & 0.7512 \\
\hline (GU189611) & R: TCACACGTAAAGTTTTTGGA & & & & & & \\
\hline WXM14 & F: GCAGCAGTAAAGCAAATGAGG & 54 & $115-140$ & 5 & 0.5128 & 0.7111 & 0.6586 \\
\hline (GU189612) & R: TTGAATTCCTTGCCTCTTCC & & & & & & \\
\hline WXM16 & F: AATGTAAGAATCAGGGGAGA & 54 & $185-225$ & 5 & 0.5531 & 0.6601 & 0.6142 \\
\hline (GU189614) & R: TCGGCAGTTTGTGGGT & & & & & & \\
\hline WXM17 & F: GAAAGGAACTTCAAGAGGC & 54 & $210-235$ & 4 & 0.2784 & 0.3062 & 0.2811 \\
\hline (GU189615) & R: GGACAGTGAGCAAAGCATC & & & & & & \\
\hline WXM18 & F: TCGATGGCGACTTGCA & 54 & $115-160$ & 5 & 0.3370 & 0.3683 & 0.3526 \\
\hline (GU189616) & R: CCTCTGCCCTGACTTGAA & & & & & & \\
\hline WXM20 & F: TCCCGATGAAAGGCACA & 52 & $145-188$ & 5 & 0.5018 & 0.6130 & 0.5684 \\
\hline (GU189618) & R: TAAAGGCGGTGATGAT & & & & & & \\
\hline WXM21 & F: CCAACAGGTCCCATCCAAC & 50 & $108-118$ & 2 & 0.4359 & 0.4415 & 0.3436 \\
\hline (GU189619) & R: GGTCGAGATTACCGATTTCAT & & & & & & \\
\hline WXM28 & F: ACGGCGGTAAAGAATC & 54 & $223-242$ & 4 & 0.3846 & 0.3927 & 0.3660 \\
\hline (GU189624) & R: AACAGGGCAGAAAGAAA & & & & & & \\
\hline WXM31 & F: TCTTATCCCGTAACCTTTCC & 52 & $180-265$ & 7 & 0.7949 & 0.8055 & 0.7747 \\
\hline (GU189627) & R: GCCTCATTTGCATGTCGT & & & & & & \\
\hline WXM32 & F: TTGTGACGCCAGAGTG & 52 & $188-216$ & 4 & 0.4799 & 0.6005 & 0.5518 \\
\hline (GU189628) & R: GCTTGTAGAGCGCCTAT & & & & & & \\
\hline WXM34 & F: AGTAAGTAAGAGTTGGATGG & 52 & $229-293$ & 5 & 0.2711 & 0.2783 & 0.2644 \\
\hline (GU189630) & R: AACAAACAACGAGGTCA & & & & & & \\
\hline WXM36 & F: CAGTGCTGCTTCAAGAG & 52 & $145-180$ & 5 & 0.3626 & 0.6416 & 0.5963 \\
\hline (GU189632) & R: ACCGAGCATCTAACCTAC & & & & & & \\
\hline WXM37 & F: CTTGTGCGGTTTTCTAT & 54 & $180-210$ & 5 & 0.5568 & 0.7449 & 0.6975 \\
\hline (GU189633) & R: TGGATGAAGTTTATGCC & & & & & & \\
\hline Average & & & & 5.1500 & 0.5081 & 0.6003 & 0.5575 \\
\hline
\end{tabular}

\section{Table 3. Summary statistics amongst seven Macrobrachium nipponense populations.}

\begin{tabular}{lccc}
\hline Population & $M N E$ & $H_{\mathrm{O}}$ & $H_{\mathrm{E}}$ \\
\hline YC & 3.5500 & 0.4718 & 0.5174 \\
PG & 3.7000 & 0.4705 & 0.5438 \\
SM & 4.7000 & 0.5731 & 0.6146 \\
JY & 4.3000 & 0.4833 & 0.5440 \\
DM & 4.6500 & 0.4987 & 0.5626 \\
JN & 4.5000 & 0.5218 & 0.5735 \\
DY & 4.4500 & 0.5372 & 0.5701 \\
Average & 4.2643 & 0.5081 & 0.5609 \\
\hline
\end{tabular}




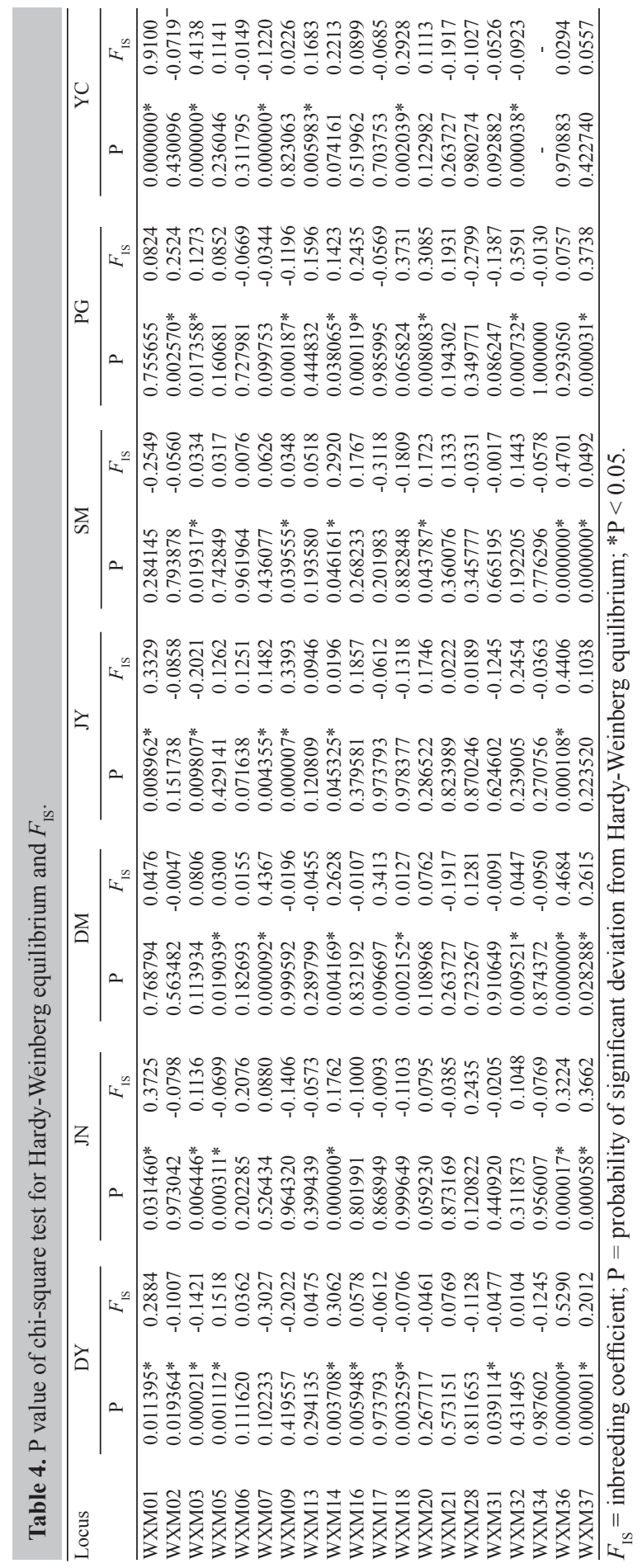


Table 5. Genetic differentiations in seven geographic populations of Macrobrachium nipponense.

\begin{tabular}{|c|c|c|c|c|c|c|c|}
\hline Population & DY & $\mathrm{JN}$ & DM & JY & SM & PG & $\mathrm{YC}$ \\
\hline $\begin{array}{l}\mathrm{DY} \\
\text { JN }\end{array}$ & $0.0177 *$ & & & & & & \\
\hline DM & $0.0172^{*}$ & $0.0203 *$ & - & & & & \\
\hline JY & $0.0418^{*}$ & $0.0488^{*}$ & $0.0525 *$ & - & & & \\
\hline SM & $0.0260 *$ & $0.0298^{*}$ & $0.0237 *$ & $0.0393 *$ & & & \\
\hline PG & $0.0538^{*}$ & $0.0572 *$ & $0.0644 *$ & $0.0791 *$ & $0.0518^{*}$ & - & \\
\hline YC & $0.0559 *$ & $0.0641 *$ & 0.0650 * & $0.0706^{*}$ & $0.0517 *$ & $0.0316^{*}$ & - \\
\hline
\end{tabular}

$F_{\mathrm{ST}}$ values are below the main diagonal and $* \mathrm{P}<0.05$.

Table 6. Analysis of molecular variance (AMOVA) for 7 geographic populations based on 20 microsatellite loci.

\begin{tabular}{lrrrr}
\hline Source of variation & d.f. & Sum of squares & Variance components & Percentage of variance \\
\hline Among populations & 6 & 68842.694 & 120.814 & $6.04 \% *$ \\
Between individuals among populations & 266 & 545368.128 & 188.547 & $9.42 \% *$ \\
Within individuals & 273 & 456773.500 & 1673.163 & $83.61 \% *$ \\
Total & 191 & 1070984.322 & 18.669 & - \\
\hline
\end{tabular}

$* \mathrm{a}=0.01$.

\section{Population genetic relationships}

The Nei unbiased genetic distances (Nei, 1978) between each two different populations was from 0.0455 to 0.2223 (Table 7). The data of genetic distance matrix (DSA) showed that populations DM and DY had the nearest genetic distance, whereas the farthest genetic distance was between populations PG and JY. The genetic relationships between populations were further confirmed by using the UPGMA in PopGen32 (Figure 1). As this phylogenetic tree shows the relationship between DM and DY was the closest. JN was clustered with DM and DY and then clustered with SM. PG and YC were also close. These four populations (DM, DY, $\mathrm{JN}$, and SM) were clustered together and then clustered with JY and finally with PG and YC.

Table 7. Inter-population genetic identification (up triangle) and genetic distances (down triangle) between 7 geographic populations.

\begin{tabular}{lccccccc}
\hline Population & DY & JN & DM & JY & SM & PG & YC \\
\hline DY & $* * * * *$ & 0.9532 & 0.9555 & 0.8938 & 0.9261 & 0.8616 & 0.8640 \\
JN & 0.0480 & $* * * * *$ & 0.9471 & 0.8742 & 0.9141 & 0.8511 \\
DM & 0.0455 & 0.0543 & $* * * * *$ & 0.8667 & 0.9343 & 0.8346 & 0.8417 \\
JY & 0.1123 & 0.1345 & 0.1431 & $* * * * *$ & 0.8937 & 0.8007 \\
SM & 0.0767 & 0.0898 & 0.0680 & 0.1124 & $* * * * *$ & 0.8570 & 0.8330 \\
PG & 0.1490 & 0.1612 & 0.1808 & 0.2223 & 0.1543 & $* * * *$ \\
YC & 0.1462 & 0.1724 & 0.1717 & 0.1827 & 0.1428 & 0.0742 & $* .9285$ \\
\hline
\end{tabular}

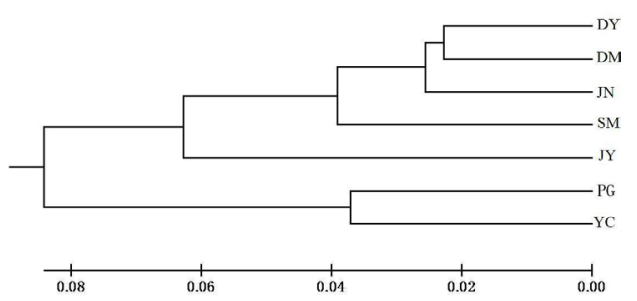

Figure 1. Cluster analysis result among seven geographic populations. Unweighted pair group method with arithmetic mean (UPGMA) in MEGA software (version 4.1) were used for this analysis. 


\section{DISCUSSION}

Genetic diversity is an important basis of germplasm resources assessment, and high genetic diversity indicates good survival capability and breeding potential (O'Connell and Wright, 1997). The mean allele number and heterozygosity are used as estimators to evaluate genetic characteristics and diversity. In the present study, the mean observed heterozygosity of Yellow River populations were from 0.4705 to 0.5731 , which was higher than that of Qiantang River ( 0.56 to 0.66$)$ and Poyang Lake (0.54 to 0.67$)$ populations, and lower than Taihu Lake wild populations (0.683 to 0.835) (Feng et al., 2011; Ma et al., 2011; Su et al., 2011), suggesting that the Yellow River populations in this study represented higher molecular diversity compared with the Qiantang River and Poyang Lake populations but had less diversity than the Taihu Lake populations. In the present study, the observed mean heterozygosity was lower than the expected mean heterozygosity for all populations, and the values within the population differentiation were positive, indicating the validity of inbreeding within those populations. Compared with previous reports on genetic diversity analysis of $M$. nipponense populations in Yangtze River, Poyang Lake, and Taihu Lake, respectively, similar results were observed in this study, in that population-locus cases exhibited departures according to the statistical significance of HWE. It is very likely that random variation and/or the small sample size might account for the HWE departures. If a population is in HWE, the value of $H_{\mathrm{E}}$ is close to $H_{\mathrm{O}}$, and the population deviates from HWE as a result of the excess and/or deficit of heterozygotes reflected by the inbreeding coefficient $\left(F_{\mathrm{IS}}\right)$ (Quan et al., 2006). Considering the fact that $H_{\mathrm{E}}$ was apparently higher than $H_{\mathrm{O}}$, heterozygote deficiency seems to be the strongest evidence for all these deviations from HWE. There is reasonable explanation that heterozygote deficiency may include natural selection, phenotypic assortative mating, and inbreeding. Such phenomena are worth paying enough attention to in germplasm conservation because it might be a potential risk for $M$. nipponense to rapidly lose genetic diversity and suffer further inbreeding depression. Through comparison of the $H_{\mathrm{O}}$ and HWE, it may be concluded that M. nipponense of the Yellow River is in a better condition, suggesting that the wild M. nipponense populations in the Yellow River have retained considerable amounts of genetic diversity within individuals. These baseline data can be effectively used in further aquaculture breeding of M. nipponense.

In this study, the pairwise $F_{\mathrm{ST}}$ coefficients showed that the Pianguan and Yinchuan populations in the middle and upper reaches of the Yellow River presented a significant difference to other populations in the lower reaches. Such a phenomenon may be attributed to the special geologic conditions of the middle and upper reaches of the Yellow River. Both the $F_{\mathrm{ST}}$ and AMOVA analyses showed that there was significant difference in population differentiation among the seven populations, which was consistent with some earlier reports on the genetic diversity studies of wild $M$. nipponense populations in different geographic locations (Fu et al., 2010; Feng et al., 2010; Ma et al., 2011). Taking our results together with literature evidence, we found that population differentiation was higher in rivers than in lakes according to the comparison of $F_{\mathrm{ST}}$ and AMOVA analyses. This could be explained by the higher capability of dispersal in lake environments. The UPGMA clustering tree based on genetic distances demonstrated that their close relationship is consistent with their geographic proximity. The pairwise genetic distances were directly related to the geographic distances, suggesting that dispersal is spatially limited owing to the geographic distance and the tendency of individuals to find mates from nearby populations rather than from distant populations. 
Genetic variations are critically important for genetic improvement of farmed populations (Gjedrem and Baranski, 2009). So far, our laboratory has reported that the breeding work of $M$. nipponense is mainly in southern China and made some progress on interspecific hybridization, which is an available way to create new germplasms and enrich breeding materials (Fu et al., 2004), but many new different breeding materials and schemes are still urgently needed to respond to the problems arising in aquaculture. The wild populations of M. nipponense in the Yellow River studied here could be good starting materials for aquaculture and for initiating a selective breeding program for genetic improvement.

In conclusion, microsatellite markers were effective in assessing the genetic variability within genotypes of $M$. nipponense, given the large number of markers identified and the high polymorphisms found, and the data suggest that this Yellow River population has a wide genetic base that is suitable for breeding. It also reminds us of the urgent need to conserve the abundant resources of M. nipponense in the Yellow River.

\section{ACKNOWLEDGMENTS}

Research supported by the National Natural Science Foundation of China (\#31272654), the National Science and Technology Supporting Program of the 12th Five-year Plan of China (\#2012BAD26B04; \#2012BAD25B07), the National Natural Science Foundation of Jiangsu Province (\#BK2012091), the Science and Technology Supporting Program of Jiangsu Province (\#BE2012334), and the Freshwater Fisheries Research Center, China Central Governmental Research Institutional Basic Special Research Project from the Public Welfare Fund (\#2013JBFM15).

\section{REFERENCES}

Botstein D, White RL, Skolnick M and Davis RW (1980). Construction of a genetic linkage map in man using restriction fragment length polymorphisms. Am. J. Hum. Genet. 32: 314-331.

Brooker AL, Benzie JAH, Blair D and Versini J-J (2000). Population structure of the giant tiger prawn Penaeus monodon in Australian waters, determined using microsatellite markers. Mar. Biol. 136: 149-157.

Bureau of Fishery, Ministry of Agriculture and P.R.C. (2009). Fisheries Economic Statistics. In: China Fishery Yearbook. China Agricultural Press, Beijing, 236.

Cai YX and Ng PKL (2002). The freshwater palaemonid prawns (Crustacea: Decapoda: Caridea) of Myanmar. Hydrobiologia 487: 59-83.

Feng JB and Li JL (2008). Twelve polymorphic microsatellites in Oriental river prawn, Macrobrachium nipponense. Mol. Ecol. Resour. 8: 986-988.

Feng JB, Wu CL, Ding HY, Hua XM, et al. (2010). Microsatellite analysis of genetic diversity in 9 wild stocks of oriental river prawn Macrobrachium nipponense in Hongze Lake. J. Fish. Sci. China 17: 1-10.

Feng JB, Wu CL, Ma KY, Ding HY, et al. (2011). Genetic structure of wild Macrobrachium nipponense populations in Taihu Lake based on microsatellite analysis. Ying Yong Sheng Tai Xue Bao 22: 1606-1614.

Fu H, Gong Y, Wu Y, Xu P, et al. (2004). Artificial interspecific hybridization between Macrobrachium species. Aquaculture 232: 215-223.

Fu HT, Qiao H, Li FJ, Wu Y, et al. (2010). Genetic diversity of Macrobrachium nipponense on a regional scale in the Yangtze River. J. Fish. China 34: 204-212.

Ge JC, Xu ZQ, Huang YH, Lu QP, et al. (2011). Genetic Variation in Wild and Cultured Populations of the Freshwater Prawn, Macrobrachium nipponense, in China. J. World Aquacult. Soc. 42: 504-511.

Gjedrem T and Baranski M (2009). Selective Breeding in Aquaculture: An Introduction. Springer, Heidelberg, Germany. Goudet J (1995). FSTAT (Version 1.2): A Computer Program to Calculate F-Statistics. J. Hered. 86: 485-486.

Klinbunga S, Ampayup P, Tassanakajon A, Jarayabhand P, et al. (2001). Genetic diversity and molecular markers of cupped oysters (genera Crassostrea, Caccostrea, and Striostrea) in Thailand revealed by randomly amplified 
polymorphic DNA analysis. Mar. Biotechnol. 3: 133-144.

Ma KY, Feng JB, Xie N, Feng XY, et al. (2011). Microsatellite analysis of genetic variation of the oriental river prawn Macrobrachium nipponense in Qiantang River. Dongwuxue Yanjiu 32: 363-370.

Milliman JD and Meade RH (1983). World-wide delivery of river sediment to the oceans. J. Geol. 91: 1-21.

Nei M (1978). Estimation of average heterozygosity and genetic distance from a small number of individuals. Genetics 89: 583-590.

O’Connell M and Wright JM (1997). Microsatellite DNA in fishes. Rev. Fish Biol. Fisher. 7: 331-363.

Peakall R and Smouse PE (2006). GENALEX 6: genetic analysis in Excel. Population genetic software for teaching and research. Mol. Ecol. Notes 6: 288-295.

Qiao H, Li FJ, Fu HT, Wu Y, et al. (2011). Isolation and characterization of 40 microsatellite loci for Oriental river prawn (Macrobrachium nipponense) and cross-species utility. Conserv. Genet. Resour. 3: 319-322.

Quan YC, Sun XW and Liang LQ (2006). Genetic polymorphism of microsatellite dna in two populations of northern sheatfish (Silurus soldatovi). Yi Chuan Xue Bao 33: 908-916.

Sambrook J and Russell DW (2001). Molecular Cloning: A Laboratory Manual, 3rd edn. Cold Spring Harbor Laboratory Press, New York.

Song KH and Kim W (2011). Isolation and Characterization of Polymorphic Microsatellites from the Oriental River Prawn Macrobrachium nipponense (Caridea: Palaemonidae). J. Crustacean Biol. 31: 138-141.

Su X, Wang GL, Feng JB, Li JL, et al. (2011). Genetic diversity of 15 Macrobrachium nipponense populations in Poyang Lake based on microsatellite analysis. Chin. J. Ecol. 30: 2007-2013.

Supungul P, Sootanan P, Klinbunga S, Kamonrat W, et al. (2000). Microsatellite Polymorphism and the Population Structure of the Black Tiger Shrimp (Penaeus monodon) in Thailand. Mar. Biotechnol. 2: 339-347.

Van Oosterhout C, Hutchinson WF, Wills DPM and Shipley P (2004). MICRO-CHECKER: software for identifying and correcting genotyping errors in microsatellite data. Mol. Ecol. Notes 4: 535-538.

Yu HP and Miyake S (1972). Five species of the genus Macrobrachium (Crustacea, Decapoda, Palaemonidae) from Taiwan. Оhти 3: 45-55.

Zhao Y, Wang H, Ji XS, Zeng YQ, et al. (2010). Isolation and characterization of 20 polymorphic microsatellite markers in Macrobrachium nipponense. Conserv. Genet. Resour. 2: 137-139. 